Vol. 10(1), pp. 1-7, January 2018

DOI: 10.5897/JASD2017.0470

Article Number: 01167 F955689

Journal of African Studies and

ISSN 2141-2189

Copyright (c) 2018

Development

Author(s) retain the copyright of this article

http://www.academicjournlas.org/JASD

Full Length Research Paper

\title{
Introducing the Jaarsa Biyyaa customary dispute settlement institution among the Horroo society of Ethiopia
}

\author{
Zerihun Abebe \\ Department of Anthropology, Wollega University, Nekemte, Ethiopia.
}

Received 21 July 2017; Accepted 27 September, 2017

\begin{abstract}
This study deals with an introduction to Jaarsa Biyyaa (Elders' council) among Horroo of Oromo society in Ethiopia. Even though numerous researches have been conducted on customary institutions of dispute settlement, there is an obvious gap of research conducted on the theme in the research area. The study addressed the Jaarsa Biyyaa customary dispute settlement institution among the Horroo society. To realize the intended objectives of the research, qualitative research approach has been adopted. Both primary and secondary sources of data and different data collection tools were used for the study. The secondary sources used have been clearly cited, and acknowledged in the thesis.
\end{abstract}

Key words: Oromo, Jaarsa Biyyaa, Horroo, dispute.

\section{INTRODUCTION}

Conflict is part of everyday human relations, and it is as such described to be part and parcel of the human life. In the human history, dispute is indivisible from social life and it happens due to different factors. In Africa where the social bonds are described to be stronger, the customary dispute settlement institutions play a vital role in settlements of disagreement and enhancing the solidarity and cohesions of the society. There are various customary dispute settlement institutions playing a significant role in handling disputes of various nature and scale in Africa (Gulliver, 1979). These institutions have attracted attentions of Anthropologists who were interested in understanding the different procedures used by the institutions in settling disputes of various natures (Bohannan, 1967; Fallers, 1969; Knutson, 1967;
Gluckman, 1956; Gulliver, 1965; Utne, 2001). Like other African countries, in Ethiopia there are various customary dispute settlement institutions, which are vibrant in settling disputes between individuals and groups (Pankhurst and Getachew, 2008; Tarekegn and Hannah, 2008; Jetu, 2011; Asefa, 2008; Haftom, 2011; Kelemework, 2011; Getachew and Shimelis, 2008; Dereje, 2008). Among the Horroo Oromo society most of the disputes are handled via customary dispute settlement institutions, especially Jaarsa Biyyaa (elders' council). Even though, Elders' council has been playing a crucial role in handling conflict there is no prior study conducted on the theme. Thus, this research tries to fill this gap by examining the customary dispute settlement institution with emphasis on the Jaarsa Biyyaa

E-mail: zdabebe@yahoo.com.

Authors agree that this article remain permanently open access under the terms of the Creative Commons Attribution License 4.0 International License 
among the Oromo of the Horroo in the North Eastern Wallaggaa. The general objective of this research is to understand nature and procedures of Jaarsa Biyyaa (elders' council) customary disputes settlement institution among the Horroo society.

The Horroo Guduru Wallaggaa is one of the zones of Oromia regional state. It is located in western part of the country. Horroo district is bordered by the Guduru and Fincha'a in the East, Bila Sayo and Abe Dongoro district in the West, Jardaga Jarte district in the North and Western Shewa zone in the South. Shambu is the capital town of both the Horroo district and the Horroo -Guduru Wallaggaa zone. Horroo district is located $310 \mathrm{~km}$ west of Addis Ababa (Finfinnee), the Oromiya regional and the federal capital.

\section{MATERIALS AND METHODS}

This research employed qualitative research methods. Both primarily and secondary sources of data were used for the study, and hence different data collection tools used were presented. The primary data are collected by observation, key informant interview, informal discussion, focus group discussion, and case study. Furthermore, this research referred to relevant academic literature on the customary dispute settlement institutions.

\section{Introducing the Jaarsa Biyyaa customary dispute settlement institution among the Horroo society of Ethiopia}

The Horroo Oromos as one of the most Ethiopian society handle dispute through both the formal and customary disputes settlement institutions. In the society, most of the disputes are resolved through indigenous conflict resolution institutions. Some of the dispute settlement institutions in the area are: llaa fi ilamee (reconciliation through disputants themselves), Jaarsa Biyyaa (the elders' council), Qalluu (the Qalluu spiritual court) and Ekeri Dubbistuu ${ }^{1}$ (reconciliation through ancestors or the soul of died person).

For the purpose of this study, the study has focused on the Jaarsa Biyyaa (Elders' Council) customary dispute settlement institution. This is mainly due to the fact that most of the disputes in the local setting are settled through the elders' council and due to the fact that it is one of the vibrant institutions in the stetting.

Different societies recognize elders in different ways. According to Bohannan (1958), an elder in the Tiv society is an older man who is responsible to lead his society and assure their peaceful existence. Likewise, in the study area, the elder means the person who knows the tradition, custom and value of his society and who serves as mediator between disputants.

\footnotetext{
${ }^{1}$ Ekeri dubbistuu is the mediator who is believed to reconcile cases with the help of the spirit of deceased individuals.
}

The term Jaarsa (Elder) among Horroo society has dual connotations. First, 'Jaarsa' means an individual who has been living long in the area. The term hints at an old age specifically to the age of a person, which is more than sixty years; however, not all individuals who have been residing in the area for long are legible to be labeled as elders' council.

The second connotation of the word 'Jaarsa' is related to the reconciliatory skills of a person. The word 'jaarsa' hence in this second interpretation refers to the symbolic element of maturity and wisdom ascribed to mediators. It indicates that the person is familiar to the customary law and has spent his time on Jaarsummaa (Act of reconciliation).

The term 'Jaarsa Biyyaa' is derived from the words 'Jaarsa' and 'Biyyaa'. The term 'Biyyaa' literally means 'country' (abode or setting). Thus, 'Jaarsa Biyyaa' means 'tan elder of the country' or 'elders of the neighborhood'. Jaarsummaa is the process of dispute settlement through the elders' council. The elders' council often happens on ad-hoc bases and it often happens when disputes arise. In this regard, Melese (2008) asserted that the 'Deira Cimma' a customarily institution found among the Walayta is an ad-hoc elected office which often assembles when a particular conflicts arise.

\section{The criteria's of elders' council}

In the study area, not everyone is legible for being selected as elders' council. Everybody is not legible for the office due to the fact that fulfilling the criteria to be the elders' council is quite complicated. Some of the criteria's for the selection of the Elders' Council in the study area are:

\section{Wisdom}

The person to be elected as the Elders' council is expected to be who is very well conversant with the norms, value, aadaa (culture) of the community and he should be someone who is respected by the society. An Elder is expected to be someone who is very well familiar with the norms, value, and he should be someone who is respected by the society. He should have the ability to manage the disputes peacefully. Also, the person ought to speak truth; he has to be somebody who is often described as a role model in the community and in his family. Similarly, Bohannan (1958) asserted that among the Tiv society a person should have the knowledge of Jural and of genealogical and personal histories of his agnates, the mastery of health and fertility granting magic qualities to be chosen participate in the elders' council. The elders should have to be confidential. According to the discussions raised in the focus group discussion (FGDs), more weight is 
given to this quality of elders because if the elders' council tells the clandestine between the disputants, this might aggravate things and might worsen disputes. The other personal qualities expected from elders are being free of nepotism and biases. The elder should be someone who is free from gossiping and backbiting.

\section{Age}

According to Mamo (2005) and Dejene (2002), age and kinship are not criterion in the selection of elders' council, but knowing the custom and culture of the Oromo society. The term elder does not inevitably demonstrate age. Any person who plays the role of mediator at a given reconciliation proceedings is selected as elders' council regardless of his age. Beside, in the study area, age is not a decisive factor in the assortments of the elders' council. Thus, any person in whichever age group is legible to be elders' council as long as he is well conversed with the local custom, and he has the qualities mentioned earlier. Furthermore, his consent is also equally required to nominate him. A person who has good knowledge of the culture, custom, law, and a person who has experience in the settlement of dispute and someone who is ready to devote his time for the reconciliation, is considered legible for the office. In the study area, elderly men dominate the reconciliation p r o c e e ding. The society considers elders as being better off than the youth in terms of their wisdom.

\section{Economic status}

Among Horroo society, wealth is not the criterion for electing an elder for reconciliation. Any person who speaks truth, and has experience in reconciliation and is considered to be wise can be involved in elders' council, regardless of his/her income. If the elder is poor and does not have someone to cover up his contribution, the society helps him in farming, threshing and harvesting in those instances when he sets out for the reconciliation proceedings. Also, if the elder has no child who herds his cattle, one of the disputants sends the child to herd the cattle until the person return from the reconciliation.

\section{Caste groups}

Moreover, the social status of an individual is criterion for recruitment to the elders' council position. According to the study informants, people like the tumtuu (black smith), faqii (leather workers) and Garboota (slaves) are those groups who are considered as having a lower social status in the community. They are considered as caste groups, and in most instances they are parts of the society ostracized from important societal positions such as dispute settlement. As a result, these groups of the society are mostly not selected for the reconciliation.

\section{Religion}

Among the Horroo Oromo society, the religious background of elders is not a criterion in the choice of elders' council. The religious leaders like the Jaarsa Waldaa (Elders of the Church) among the protestant, Qalluu and sheiks among the Muslim participate actively in reconciliation of various disputants. These religious leaders often attend the session to lead the oath taking ritual. Generally, when one person is selected as the elders' council the religious background of the person is not a crucial criterion. Also, gender is another criterion in the selection of the elders' council among the Horroo society. The males and females have no equal opportunity to be selected as elders' council. Mostly, the institution favors the males in the study area.

\section{Conditions of calling for elders' council}

There are different factors that are important for electing elders' council. The major factors mentioned by informants are four. The first circumstance is situations where either the plaintiff or defendant takes their cases to elders' council on their own initiative. Among the study area both disputants often take the initiative to take their cases to the elders' council. In few instances, offenders also report their cases, and initiate reconciliation. One of the study key informants witnessed the following story that an offender reported to the elders' council after the person confesses that he has committed an offense:

"I fought with one person from my neighborhood on a plot of land. Then I threw spear to him; although the spear did not hurt him. I knew my offense and rushed to the Jaarsa Biyyaa and informed them to reconcile me with the person. If I was silent, he would have reported the case to the police and I would have been thrown to jail. We handled our case with the Jaarsummaa". Source: (Interview with Addunyaa, at Saqala, August 10/2016).

The disputants select elders who they think will reconcile them. On simple disputes, both the plaintiff and the dependents select two elders each. Normally, the disputants pick elders who know their cases very well, than strangers. The second circumstance, which calls for the need to have elders' council, is situations when the elders take the plan by themselves to reconcile disputants. This kind of elders' council is engaged in the settlement process, often in those instances where by the disputed cases are considered to be serious. On this occasion, the elders' council by their own initiative 
reconciles disputants. In this regard, Mamo (2008) called these kinds of elders 'self-initiated elders'. He asserted that the self-initiated Jaarsa Biyyaa involves in disputes settlement on its own initiatives and freewill. The third instance is situations whereby neighbors, friends, and relatives of disputants call the elder to settle the matter. This situation is hence an occasion when the quantities call for reconciliation of the cases through elders.

Fourthly, the elders' council is called upon by government officials and state institutions like district court, the police and kebele social courts. Here the involved government bodies request for the consent of the disputed parties. The court refers the disputants to elders' council. The civil cases and some minor crime cases are referred to the elders 'council. During the researcher's field work, he came across one case that has been referred from the court to elders' council after the lawyers at the state court made the disputants to elect elders. It occurs when the disputants agree with each other, before the court, to handle their dispute through reconciliation.

\section{The calendar and venue of elders' council}

The elders' council helps the society to handle a dispute at its root, before it distresses the harmony of the society. This section presents accounts on the venue and time of the elders' assembly.

\section{Venue}

Jaarsummaa (reconciliation) is often held under the tree and on the open free space. The elders take a seat on the green grass facing each other. On this session, the disputant's do not sit next to each other. The criminal sits on the left hand and the plaintiff sits on the right hand. The offender sits on the left hand, to symbolize that he/she did a crime. In this regard, Mamo (2008) discuss that on Jaarsummaa session, people that attend the resolution sit facing each other. As the gathering gets larger in size, this structure may be changed to a circular shape. The venue often chosen for reconciliation is under the shade tree or on the adjoining land.

\section{Day}

The elders' council proceedings are commonly conducted on Sundays. The society considers Sunday as reconciliation day. On Sunday the elders' council spends their time reconciling disputants. The elders reconcile disputants from early morning until night, depending on the number of cases brought to the council. In this regard, one of the study key informants substantiated that "on Sunday we reconcile disputants". The other reason given for having the hearing on Sunday is because Sunday is the official weekly holiday when people are resting and are free from labor.

In the case of serious disputes, the reconciliation is held on Tuesday, Thursday and Saturday. The society considers these days as full days. If it is a serious physical injury, then reconciliation might be conducted swiftly. It helps to minimize the suspected retributions between the disputants. In such exceptional cases of severe fights, the elders' council session might be held on the days of any venerated saint days like St. Miriam and St. Michael.

The elders' council session is not conducted on the days like Monday, Wednesday and Friday. It is because the society considers these days as odd days. Furthermore on these days, the society refrains from having different celebrations like wedding ceremony, and engaging in agricultural activities; on the other hand the reconciliation for homicide cases is held on the odd days in the study area. This is because homicide is (daba) abnormal, hence it is conducted on the incomplete days. The elders' council proceedings take place early in the morning before elders wash their hands and have breakfast. This is to avoid any possible mismanagement of cases that might result from instances where elders have been drunk.

\section{Brief note on the elders' council procedure}

On the day of the reconciliation, the elders start the meeting by blessing and praying to Waaqaa (God) about the cases that they are going to handle. The Oromo society opens any types of the rituals and ceremonies with blessing of the senior elders, and praying to the creator. In the study society, the senior elder opens the reconciliation session by blessing the meeting.

After the senior elders bless the session, the reconciliation starts. Sometime the disable person like handicap makes the elders take oath to be fair throughout the hearing. It helps the elders to speak truth without favoring one of the disputant's, but this is not often the case in all reconciliation proceedings. Following this, the chairman of elders opens the hearing. $\mathrm{He}$ introduces the disagreement between disputants to the elders.

On reconciliation, the representative of the elders stands and asks the disputants to call their grantor. The disputants call their grantor either from the elders or from the peoples attending the session. The plaintiff first calls his/her grantor according to interview with the study informants and observation during the fieldwork. The representative of the elders asks the plaintiff, 'call for us grantor from the relatives'. The plaintiff stands and calls one person from the people attending the elders' council session. The representatives of the elders' council provides oath for the grantor of the plaintiff. He gives 
oath saying 'Will you be a grantor to him/her, do you swear in the name of your relatives? The grantor of the plaintiff says 'I am his/her grantor, may the relative die.'

After the plaintiff calls his /her grantor, the defendant calls his/her grantor. The defendant calls one person attending the meeting for his/her grantor. The representative of the elders provides oath for the grantor of the defendant and makes him /her take similar oath as the former. The grantor of the disputants play crucial role in the reconciliation of the disputants in the study area. The grantors control the interruption of the disputants during the joint decision on the reconciliation session. They convince the disputants to accept the decision of the elders. Since, the grantor took the responsibility on behalf of the disputants, when the offender fail to pay the compensation, the elders may appeal to the grantor to intervene. In Horroo society, after the himataa (plaintiff) and himatamaa (defendant) call their grantor, the elders' council asks the disputants to narrate their problems.

Lewis (1984b) argued that whether or not the elders listen to the opinion, information and claims of each party in the presence of the opponent is determined by the situation. Wherever the case is serious and possibly provocative of the further heated argument, the mediators employ as strategy of hearing the claim of each in the opponent. The disputants may/ may not hear the claim of the opponent in the society under discussion. Hence such separate hearing is based on the magnitudes of the disputes. If the dispute is grave, plaintiffs are asked to go away from the forum. The plaintiff and defendants are asked to keep certain distance in order not to hear the claim of one another. The disputants separated from the session, on the grave disputes like the serious physical injuries and homicide cases. It avoids disturbance and aggressive behavior of disputants that may occur on the forum according to interview with my informants.

Also, on homicide and serious injuries, the elders' council delays the day of the settlement. It helps the disputants to cool down. Similarly, Nicolas (2007) asserted that in the serious case of the elders' continuing mediation activities, thus allowing time for quarreling parties calm down. But, if the dispute is simple, the disputants can hear the claim of the opponent. On the other hand, the joint decision is given for the disputants on the two occasions. First, if the information from the plaintiff and defendant mis-matched each other. Second, if the dispute between the disputants is uncomplicated, both the plaintiff and defendant be seated together with the elders' council and can hear complaint of one another.

The person who reports his/her case to the elders' council on the session always standup and presents the claim to the elders. According to observation during the fieldwork, when the plaintiff presents his/her cases, the defendant goes away from reconciliation session. The elders tell the defendant "please, give us your ears". This is an indirect and polite way of asking him/her to go away from the meeting for a while; however, there is a time when the disputing parties made joint decision in front of the elders' council. The rationale of the open decisions is to see truth from right and left. On this joint decision, the plaintiff and defendant are not allowed to interrupt the idea of one another. If the ideal interruption took place, the grantors of the disputants have the responsibility to handle it. But, the disputants can react to each other peacefully. The plaintiff first narrated the matter to the elders' council. The plaintiff informs the sources of the disputes, where the dispute happen, how it took place and their prior relationship to the elders' council. During this time, the elders appropriately follow up his/her narration and they may ask the plaintiff for clarifying some points.

The plaintiff separated from session after he/she reported his/her claim. The elders' council calls the defendant and asks him/her to narrate his/her side of the case. The elders' council inquires the defendant of accounts of the plaintiff are true. The elders made the disputants to inform about the disputes from the launch to the end. After that, the elders separate the defendant from the meeting. On this occasion the elders deeply discuss the issue from the disputants' idea and reconcile the disputing parties based on the information gathered from both parties. But, if the report of the disputants is far distance from the reality the elders' council begins looking for evidences. According to my informants, mostly the elders' council did not use eyewitness for evidences and it only happens under such exceptional circumstances.

The elders as a group of mediators often consult the victim and offender referring to the norm, value, custom and rules to move them to an acceptable proposed solution. The elders' council gathers information from the disputants themselves in the study area. If one of the disputing parties does not accept the claim of the other, the elders' council collects evidences. The elders' council collects the evidences from different sources using different mechanisms.

First, the elders begin searching for the basic sources of the dispute from the eyewitness. Dejene (2002) discussed that the elders gather full information from the disputants themselves. It is uncommon that they look for witness to testify the issue under litigation except in few cases. The study data totally confirm its assumption. Among the Horroo society, the elders' council mostly gathers information regarding the disputes from disputants themselves. On rare cases, the elders' council, gather the information on the disputants from the spectators. If the elders' council did not get full information, they informed the disputing parties to bring their eyewitness for the next session. Until the second reconciliation session, the elders look for the information.

The disputants bring their spectators for the next 
session. The eyewitness come, the elders provides oath for the spectators. It helps to keep away the eyewitness from the bias. According to the study informants, the eyewitness customarily is believed not to take one side of the disputants. It is because the spectators dread the curse and oath of the elders' council. The observers report what he/she observed and heard on the dispute.

The elders' council makes the different disputing parties, and the witnesses swear oath of innocence. If one person hurts the other in the absence of an observer, the plaintiff often asks to take the offender to the Odaa Bulluq tree. Odaa Bulluqi is a place where the ritual of swearing oath is conducted via the elders' council. Often the wrongdoer confesses before making the oath as lying at this places believed to result in severe misfortune. The elders' council deeply discusses the matter, based on what they observed, heard from the joint decision and sometimes from the spectators. The elders' council begins to consult the disputants to reach on agreement. The elders consult the plaintiff to leave the matter in their hand.

The elders' council provides advices and consults the disputants. For instance, they say 'let alone mankind; but the teeth and tongue get in to dispute'. They also say 'all human beings are liable to make mistake, but those who learn from their mistakes are matured'. The elders also say to the disputants let your cases remain here it spreading out'. In the study area, the disputants react against verdicts of the elders' council. The criminal may react against the judgment of the elders on compensation. Also, the plaintiff may counter argue against verdict of the elders' council, when she/he is totally seen as the offender.

The elders' council uses different proverbs, when either or both of the disputants fail to accept the judgment of the elders' council. Also, the elders use different bargaining mechanisms in the study area. The elders' council advises them by referring to the norms, value and culture of the society. They said to the disputants "please accept our reconciliation in the name of God. They also say "please leave the matter in the name of the creator and earth". They said "a person who gives up on a dispute has left it in love of his relatives while the one who did not give up the dispute is the one to be cursed by his relatives".

The elders' council used these sayings to make the disputants cool down and motivate them to accept their reconciliatory ideas. The representative of the elders' council informs the final decision of the elders' council to the plaintiff. Also, he informs the plaintiff that he/she has truth. If both accuser and accused person accept the decisions of the elders' council the reconciliation ceremonies take place. If one of the disputing parties denies the decisions of the elders, they postpone the reconciliation for the next time. This appointment helps the disputants to cool down up to the coming meeting. In line with this, there is one proverb in the study area 'a case that is postponed and a liver that is let to stay over nights becomes a meat".

The grantors of each disputant have requested the disputants to reach an agreement for the next session. The grantors solicit the disputants saying "the eyes of the elders is not good, don't make the elders too see you next time, accept the decision of the elders". The eye in this context is used as a metaphor to refer to the potential harm that might affect the disputants if they fail to accept words of elders.

Moreover, the relatives of the disputants prepare disputants to accept the decisions of the elders' council. On the second reconciliation, the disputants easily reach an agreement. It is due to the influences disputants' relatives, families and the elders' council has on the disputing parties. Besides, the whole society plays essential roles to bring harmony between the disputants. For instance, before the disputants report their case to the elders' council, the relatives of the disputants endeavor to bring the disputants into harmony. Especially, if the disputants are relatives, the elders of the ancestors not success, they may report the cases to the elders' council.

The judgment of the elders' council is based on the decisions of the majority. The elders' council deeply discuss with each other, until they have reached on consensus. The elders who attend the meeting give ideas on the report of the disputants and on the spectators. If elders' council reaches on the same agreement, they call the disputants and the representative of the elders announces the judgment to the disputants. If the disputants agree on the conclusion, the elders write the reconciliation agreements in the three copies. One copy of the agreement is given to the chair of the elders, and two of the copies are given to two disputants.

However, if the case of the disputants was first sent from the formal court, the elders' council prepares the reconciliation agreement in the four copies. This is because one copy of the reconciliation agreement has to be sent to the court. On this occasion, the court closes the files of the disputants. However, if the disputants did not reach on the agreement, the files of the disputants remain open for the disputants to get final decisions through the formal court.

If the disputants accept the verdict of the elders' council, reconciliatory rituals take place. The reconciliatory ritual includes hand shaking and kissing. This reconciliatory ritual symbolizes the reconciliation of disputants, in the study area. The collector of elders' council stands and facilitates disputants to shake and kiss the hand of each other. The elders' council makes the disputants to communicate with each other, when the disputants have communication problem that the society called 'walooduu'.

According to culture of the society, the senior elder who started on the reconciliation meeting through blessing, 
closes the session by the blessing. After senior elder closed the session with blessing refreshments are provided, dishes served on such occasions are chumboo (bread coat with butter), budeena (injera) and bread. If the reconciliation is related to serious offenses like homicide cases, an animal (sheep and bull) has to be slaughtered. This is mainly to symbolize that the blood has been replaced with the slaughtered animal. The feast to be held at the end of each session have a crucial roles in the rebuilding the harmony of the disputants. It is believed to avoid sense of revenge between the disputants and their families.

To sum up, dispute is not separated from social life of human beings. This dispute is either resolved through customary or formal dispute settlement institutions. Among the Horroo Oromo society, most of the dispute which took place at different level is resolved via Jaarsa Biyyaa (elders' council). Elders selected for the institution based on the different criteria like, age, wisdom, economy, social status, religion and sex. The elders' council started their reconciliation with the blessing of senior elders. The elders' council bring the disputants in agreement based on the information they got from disputants, eyewitness and through swearing oath. The elders' council brings disputants without identifying loser and winner of the case. As a result, it avoids the sense of revenge among the disputing parties. After reconciliation ceremony is over, this is symbolized by shaking the hands of the disputants, the elders close up the assembly with blessing from senior elder.

\section{CONFLICT OF INTERESTS}

The authors have not declared any conflict of interests.

\section{REFERENCES}

Bohannan L (1958). Political aspects of Tiv social organization. In J. Middleton and D. Tait (eds.), Tribes without Rulers: Studies in African Segmentary Systems. 1(4):33-66.

Dejene G (2002). Some Aspects of Conflict and Conflict Resolution among Waliso Oromo of Eastern Macha, With Particular Emphasis on the Guma. Department of Social Anthropology: Addis Ababa University
Dereje F (2008). Customary Dispute Resolution in Gambella region the case of Nuer". In Pankhurst. http://pubman.mpdl.mpg.de/pubman/faces/viewltemFullPage.jsp?ite mld=escidoc\%3A922246\%3A1

Fallers L (1969). Law without Precedent. Chicago: University of Chicago Press.

Haftom T (2011). Rural Land Dispute Settlement Mechanisms in Tigray: the Case of Humera. MA.

Hannah T, Tarekegn A (2008). Making Peace in Ethiopia: Five Cases of Traditional Mechanisms for Conflict Resolution. Peace and Development. Addis Ababa; Ethiopia.Thesis Submitted To the School Of Graduate Studies, School Of Law, Addis Ababa University.

Gulliver P (1979). Disputes and Negotiations: A Cross- Cultural Perspective. London: Academic Press, Inc.

Jetu $E$ (2012). Mediating criminal matters in Ethiopian criminal justice system: The prospect of restorative justice system. Oromia Law J. 1(1):99-143.

Kelemwork T (2011). Conflict and Alternative Dispute Resolution among the Afar Pastoralists of Ethiopia". Afr. J. Hist. Cult. 3(3):38-47.

Mamo H (2005). Land Disputes Settlement in a Plural Institutional Setting: The Case Of Arsii Oromo Of Kokossa District, Southern Ethiopia”. African Study Monographs. 29:125-135.

Nicolas A ( 2007). From Process to Procedure: Elders' Mediation and Formality in Eastern Shewa, Ethiopia. Dissertation Zur Erlangung Des Akademischen Der Freien Universitat Berlin Fachbereich Ehnologie.

Pankhurst A, Getachew A (2008). Grass-Roots Justice in Ethiopia: the contribution of Customary Dispute Resolution. Addis Ababa: Etudes Ethiopiennes. 2:1-77.

Radcliffe- Brown AR (1952). Structure and Function in Primitive Society. London: Cohen and West.

Utne BB (2001). Indigenous Conflict Resolution in Africa, a draft presented to the week end seminar on indigenous solutions to conflicts held at the University of Oslo, Institute for Educational Research $23-24$ of February. 